\title{
ANALISA PROTEKSI DIFFERENSIAL PADA GENERATOR DI PLTU SURALAYA
}

\author{
Wahyudin SN ${ }^{1}$, Retno Aita Diantari ${ }^{2)}$, Teuku Mardhi Rahmatullah ${ }^{3)}$ \\ Teknik Elektro, Sekolah Tinggi Teknik - PLN \\ 1'wahyudin.SN@sttpln.ac.id \\ 2retno_aita@yahoo.co.id \\ 3TeukuMR@gmail.com
}

\begin{abstract}
Power plants produce electrical energy that will be distributed to consumers. Hence, the power plant is expected to be in a condition which means it can reliably provide electricity continuously with good quality. So as to improve the reliability and continuity of service, the operation of power systems require a safety equipment or protection system to prevent disturbances that disrupt the system. Protection system is an important component to maintain the continuity and reliability of the distribution of electrical energy. Protection system serves to protect equipment from damage in the event of disturbances and minimize disruptions from spreading. With good protection system, the unwanted loss can be avoided, especially in the vital equipment such as generators and transformers. One of the equipment that plays a role in the protection system is a differential protection relays are used to protect generators and transformers. This relay protects the generator and transformer from internal disturbances such short circuit between phases or short circuit of phase to ground. This rele works based on the current setting and operating time has been determined so that it can work quickly and precisely targeted.
\end{abstract}

Keywords : Protection, Relay Differential, Power Generator.

Abstrak : Pembangkit tenaga listrik berperan menghasilkan energi listrik yang akan disalurkan kepada konsumen. Oleh Karena itu, pembangkit tenaga listrik diharapkan berada dalam kondisi andal yang artinya dapat menyediakan tenaga listrik secara kontinu dengan kualitas yang baik. Sehingga untuk meningkatkan keandalan dan kontinuitas pelayanan pengoperasian sistem pembangkit memerlukan suatu peralatan pengaman atau sistem proteksi untuk mencegah terjadinya gangguan yang menganggu sistem. Sistem proteksi merupakan komponen penting untuk menjaga kelangsungan dan keandalan penyaluran energi listrik. Sistem proteksi berfungsi untuk melindungi peralatan dari kerusakan pada saat terjadinya gangguan serta meminimalisir gangguan agar tidak meluas. Dengan sistem proteksi yang baik, maka kerugian yang tidak diinginkan bisa dihindarkan, terutama pada peralatan vital seperti pada generator dan transformator. Salah satu peralatan yang berperan dalam sistem proteksi adalah rele proteksi diferensial yang digunakan untuk melindungi generator dan transformator. Rele ini melindungi generator dan transformator dari gangguan-gangguan internal seperti hubung singkat antar fasa atau hubung singkat dari fasa ke tanah. Rele ini bekerja berdasarkan setting arus dan waktu operasi yang sudah ditentukan sehingga bisa bekerja dengan cepat dan tepat sasaran.

Kata Kunci : Proteksi, Rele Differensial, Generator Pembangkit.

\section{PENDAHULUAN}

Salah satu pembangkit yang menghasilkan listrik dari berbagai sumber yang tersedia di Indonesia, yaitu Pembangkit
Listrik Tenaga Uap (PLTU). Pembangkit ini menggungakan sumber alam batu bara sebagai bahan bakar utamanya. Perubahan energi yang terjadi pada 
pembangkit, diawali dengan proses pembakaran yang menghasilkan uap panas (energi thermal) kemudian dari uap panas tersebut diubah menjadi energi mekanik oleh turbin dan terakhir dari energi mekanik menjadi energi listrik. Produksi energi listrik dilakukan secara terus menerus selama 24 jam tanpa henti, kecuali terjadi kerusakan atau waktunya utntuk peemeliharaan. Sistem tenaga listrik merupakan suatu sistem yang cukup kompleks dengan menggunakan peralatan -peralatan konversi energi seperti boiler, turbin, generator, kondensor, transformator, dan masih banyak lagi yang digunakan. Setelah listrik diperoleh dan didistribusikan ke konsumen, tentu saja jumlah listrik tersebut harus dapat memenuhi kebutuhan konsumen yang ada. Jika suplai listrik terhenti hanya beberapa menit saja, bisa di bayangkan berapa banyak aktifitas yang terhenti atau mungkin bisa menyebab kan kerugian yang sangat besar. Oleh karena itu kelancaran operasi serta kehandalan sistem menjadi syarat yang mutlak dari suatu sistem tenaga listrik agar dapat membangkitkan dan menyalurkan energi listrik sampai ke konsumen.

Salah satu hal yang penting pada sistem tenaga listrik adalah pengaman terhadap peralatan yang digunakan dari segala macam gangguan. Bagaimana baiknya suatu sistem, gangguan tidak bisa sama sekali dihindarkan. Gangguangangguan di dalam sistem tenaga listrik sangat mengganggu bahkan bisa sampai merusak peralatan itu sendiri. Sistem proteksi selain harus mengamankan peralatan listrik terhadap gangguan, juga berfungsi melokalisir gangguan. Oleh karena itu pengaman sangat di perlukan pada sistem tenaga listrik.

Salah satu pengaman pada peralatan listrik adalah rele differensial. Rele differensial merpakan suatu rele yang prinsip kerjanya berdasarkan keseimbangan (balance), yang membandingkan arus-arus sekunder transformator arus (CT) yang terpasang pada terminalterminal peralatan atau instalasi listrik yang diamankan. Rele digunakan antara lain pada generator, transformator daya, bus bar, dan saluran transmisi. Rele differensial adalah suatu alat proteksi yang sangat cepat bekerjanya dan sangat selektif berdasarkan keseimbangan (balance) yaitu perbandingan arus pada kedua sisi saluran melalui suatu perantara yaitu trafo arus (CT). Dalam kondisi normal, arus mengalir melalui peralatan listrik yang diamankan. Maka penulis akan menganalisa proteksi rele diferensial pada generator PLTU Suralaya.

Tujuan dan manfaat dari penelitian ini adalah untuk mengetahui setting rele diferensial yang tepat pada generator PLTU Suralaya.

\section{LANDASAN TEORI}

\subsection{Sistem Proteksi}

Gangguan pada pusat pembangkit listrik dapat terjadi kapan saja, untuk itu diperlukan sistem proteksi, yang berfungsi selain mengamankan peralatan pada pusat pembangkit juga untuk melokalisir dampak dari gangguan. Alat pendeteksi gangguan adalah rele, yang selanjutnya memberi perintah kepada trip coil untuk membuka pemutus tenaga (PMT).

Persyaratan utama sistem proteksi yaitu kepekaan (sensitivity), keandalan (reliability), selektif (selectivity), kecepatan (speed).

1. Kepekaan (sensitivity)

2. Keandalan (reliability)

3. Selektif (selectivity

4. Kecepatan (speed),

\subsection{Sistem Kelistrikan di PLTU Suralaya}

PLTU Suralaya terdiri dari unit dengan total kapasitas sebesar 3400 MW, unit 1 sampai unit 4 memiliki kapasitas sebesar $400 \mathrm{MW}$ dan unit 5 sampai unit 7 memiliki kapasitas sebesar $600 \mathrm{MW}$. Sehingga keluaran dari generator $23.5 \mathrm{kV}$ di step up oleh transformator menjadi $500 \mathrm{kV}$. Sehingga dari sistem $500 \mathrm{kV}$ di step down ke tegangan $150 \mathrm{kV}$ dan dari $150 \mathrm{kV}$ langsung di step down ke tegangan $20 \mathrm{kV}$.

\subsection{Sistem Proteksi di PLTU Suralaya}

Rele proteksi generator adalah peralatan ukur yang dapat mendeteksi besaran-besaran listik yang ada hubungan dengan gangguan atau ketidaknormalan dalam suatu sistem tenaga, yang kemudian memisahkan bagian yang terganggu (trip) atau hanya memberi 
tanda alarm saja. Besaran-besaran dasar listrik yang berubah selama kondisi adanya gangguan adalah tegangan, arus, sudut fasa (arah), frekuensi dan lain-lain.

Secara umum pengamatan pada generator dapat dibagi menjadi dua bagian besar, yaitu:

a. Pengaman utama generator

Pengaman utama generator yaitu pengamanan pada generator yang dapat memberikan sinyal trip pada PMB sehingga secara langsung dapat menjatuhkannya.

b. Pengamanan bantu generator

Pengamanan pada generator yang tidak secara langsung dapat menjatuhkan PMB, namun demikian dapat membunyikan alarm jika ada gangguan ataupun sesuatu yang abnormal pada sistem tenaga.

Pada generator PLTU Suralaya terdapat beberapa rele proteksi yaitu Ground Protective Relay (64SNG), Loss Of Excitation Relay (40G), Directional Power Relay (32G), Reverse Phase Relay (46GA \& 46GT), AC Over Current Relay (51VG), Instantaneous Over Current Relay (50G), AC Over Voltage Relay (59GA \& 59 GT), Frequency Relay (81GL \& $81 \mathrm{GH}), A C$ Under Voltage Relay (27G), Voltage Balance Relay (60G), dan Differential Protective Relay (87G \& 87GT).

Tegangan keluaran generator sebesar $23.5 \mathrm{kV}$ dinaikkan menjadi $500 \mathrm{kV}$ oleh transformator generator. Pada transformator generator terdapat beberapa rele proteksi yaitu Over Current Relay (51T), Ground Fault Relay (51NT), Differential Relay (87NT \& 87GT), Thermal Relay (26T \& 26QT), Liquid or Gas Pressure (63T \& 63QQT), Rectifier Element Protective Relay (71T \& 71QT), dan Thermal relay for rotating machine (49T).

\subsection{Rele Proteksi (Protection Relay)}

Rele adalah suatu alat yang apabila diberi energi oleh besaran-besaran sistem yang tepat dapat memberi indikasi suatu kondisi abnormal. Apabila kontak-kontak relay menutup, maka rangkaian-rangkaian trip pemutus tenaga yang terkait mendapat energi dan kontak-kontak breaker membuka, mengisolir bagian yang terganggu dari sistem. Rele proteksi dapat dikasifikasikan berdasarkan fungsi atau kegunaannya. Berikut ini adalah klasifikasi rele berdasarkan fungsi atau kegunaannya :

\subsection{Rele differensial}

Proteksi differensial mempunyai bentuk yang bermacam-macam tergantung dari peralatan yang diamankan. Pengertian itu sendiri mengandung unsur membedakan satu dengan yang lainnya. Semua besaran yang masuk ke peralatan proteksi seperti sudah di jelaskan tadi bahwa gangguan yang terjadi pada suatu alat bisa disebabkan karena arus hubung singkat antara atau arus hubung singkat ke tanah. Proteksi differensial harus bisa mendeteksi gangguan ini. Jika perlatan proteksi bekerja maka sesungguhnya sudah terjadi kerusakan didalam alat tersebut yang menimbulkan arus hubung singkat. Proteksi differensial dalam hubungan hal ini bertugas meluasnya kerusakan tersebut. Oleh karena itu proteksi differensial harus bekerja cepat tanpa waktu tunda.

\subsubsection{Prinsip kerja proteksi differensial}

Prinsip kerja proteksi differensial adalah membandingkan dua besaran arus dan fasa anatara dua titik pada batasanbatasan daerah pengaman. Jadi dalam hal ini digunakan arus sebagai besaran ukurnya, jika pada peralatan yang diamankan tidak terjadi gangguan atau gangguan tersebut brada diluar daerah yang diamankan maka nilai arus dan fasa mengalir pada trafo arus CT 1 dan CT 2 adalah sama atau mempunyai perbandingan nilai arus serta persesaran sudut fasa terten tu, sehingga relai tidak akan bekerja.

Tetapi jika terjadi gangguan pada peralatan yang diamankan, maka akan terjadi perbedaan arus atau perbandingan arus berubah serta perubahan sudut fasa yang akan menyebabkan relai differensial akan bekerja. Adapun cara membandingkan 11 dan 12 yaitu dengan membandingkan besarnya nilai dan sudut fasa pada arus sekunder. Batas-batas pengaman proteksi differensial dibatasi oleh trafo arus CT 1 dan CT 2. 


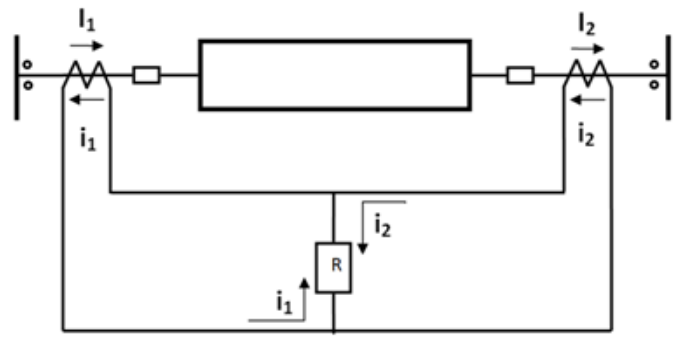

Gambar 2.1. Proteksi Difetensial dalam keadaan normal

Pada keadaan normal atau gangguan berada diluar daerah pengaman maka arus yang mengalir pada rele adalah $I_{1}=I_{2}$ dimana :

$I 1$ = arus sekunder yang mengalir pada trafo arus CT 1

12 = arus sekunder yang mengalir pada trafo arus CT 2

Dengan menganggap suatu hal yang ideal serta pemilihan trafo arus CT 1 dan CT 2 sama atau sesuai dengan transformasi trafo daya, maka selama bekerja pada keadaan normal (tidak ada gangguan) ataupun ada gangguan diluar daerah pengamannya, arus sekunder i1 dan i2 akan mempunyai nilai yang sama tetapi dengan arah vektor yang berlawanan, sehingga dari hubungan di atas didapat :

$I_{d(\text { idea } 1)}=0$

Dalam hal ini rele tidak bekerja karena tidak ada arus yang melalui rele.

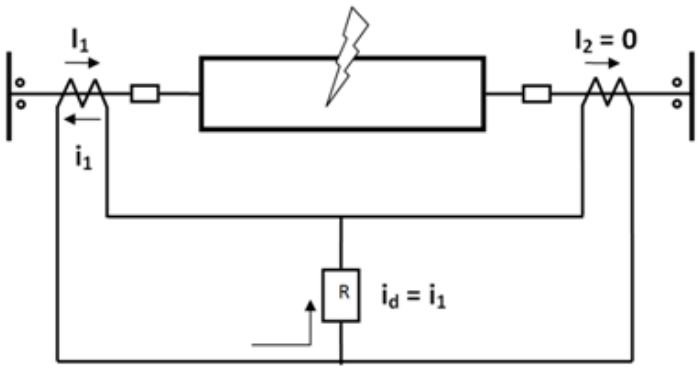

Gambar 2.2. Proteksi Diferensial dengan sumber gangguan satu arah.

Jika terjadi gangguan hubung singkat didalam daerah pegamannya maka arus yang mengalir pada CT 1 akan menjadi besar sedangkan arus yang mengalir pada CT 2 akan mendekati nol.

Dengan demikian arus sekunder i1 menjadi besar dan arus sekunder i2 akan mendekati nol, hal ini terjadi karena arus gangguan IF yang besar hanya mengalir pada satu sisi seperti yang terlihat pada gambar berikut. Sehingga sesuai dengan gambar diatas id $=\mathrm{i} 1$. Karena i2 $=0$, maka : id = i1

Dalam hal ini berarti adanya arus id = i1 yang cukup besar akan mengalir melalui rele, dengan demikian rele akan akan bekerja dan memberikan sinyal trip pemutus tenaga yang berada di kedua sisi dari peralatan listrik yang diamankan karena terjadi gangguan dipisahkan dari jaringan yang bertegangan.

\subsection{Gangguan Hubung Singkat Satu Fasa ke Tanah}

Gangguan yang sering terjadi pada sistem tenaga listrik merupakan gangguan asimetris sehingga memerlukan metode komponen simetris untuk menganalisa tegangan dan arus pada saat terjadinya gangguan. Gangguan yang terjadi dapat dianalisa dengan menghubung-singkat semua sumber tegangan yang ada pada sistem dan mengganti titik (node) gangguan dengan sebuah sumber tegangan di titik gangguan tersebut. dengan menggunakan metode ini sistem tiga fasa tidak seimbang dapat direpresentasikan dengan menggunakan teori komponen simetris yaitu berdasarkan komponen urutan positif, komponen urutan negatif dan komponen urutan nol.

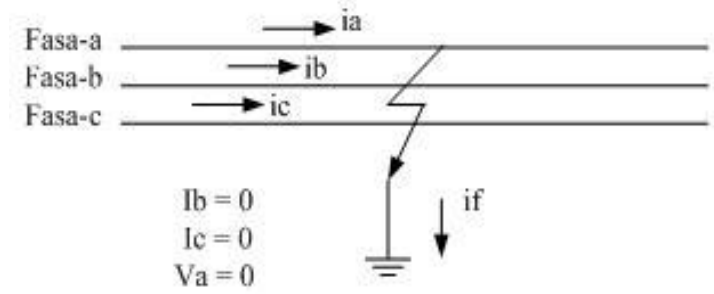

Gambar 2.3. Gangguan hubung singkat satu fasa ke tanah

$I_{\mathrm{A} 1}=\frac{V_{\mathrm{f}}}{Z_{0}+Z_{1}+Z_{2}}$

Keterangan :

$V_{f}=$ Tegangan di titik gangguan sesaat sebelum terjadi gangguan

$Z_{0}=$ Impedansi urutan nol dilihat dari titik gangguan

$Z_{1}=$ impedansi urutan positif dilihat dari titik gangguan

$Z_{2}=$ Impedansi urutan negatif dilihat dari titik gangguan 


\subsubsection{Gangguan Hubung Singkat Dua Fasa}

Pada gangguan hubung singkat fasa ke fasa, arus saluran tidak mengandung komponen urutan nol dikarenakan tidak ada gangguan yang terhubung ke tanah.

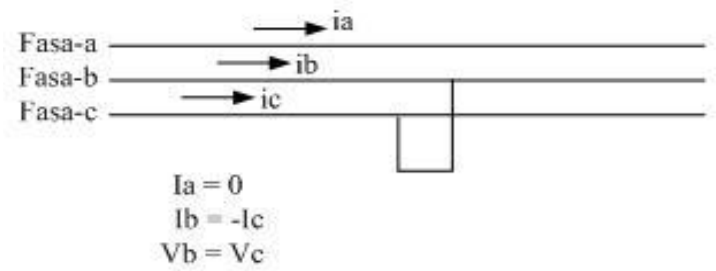

Gambar 2.4. Gangguan hubung singkat dua fasa

$$
I_{a 1=\frac{V_{f}}{Z_{1}+Z_{2}}}
$$

Keterangan :

$V_{f}=$ Tegangan di titik gangguan sesaat sebelum terjadinya gangguan

$Z_{1}=$ Impedansi urutan positif dilihat dari titik gangguan

$Z_{2}=$ Impedansi urutan negatif dilihat dari titik gangguan

\subsubsection{Gangguan Hubung Singkat Dua Fasa ke Tanah}

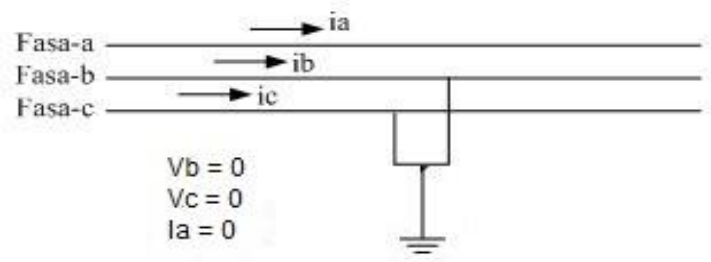

Gambar 2.5. Gangguan hubung singkat dua fasa ke tanah

$I_{A 1}=\frac{V_{f}}{Z_{1}+\frac{Z_{2} Z_{0}}{Z_{2}+Z_{0}}}$

Keterangan :

$V_{f}=$ Tegangan di titik gangguan sesaat sebelum terjadinya gangguan

$\mathrm{Z}_{0}=$ Impedansi urutan nol dilihat dari titik gangguan

$Z_{1}=$ Impedansi urutan positif dilihat dari titik gangguan

$\mathrm{Z}_{2}=$ Impedansi urutan negatif dilihat dari titik gangguan

\subsubsection{Gangguan Hubung Singkat Tiga Fasa}

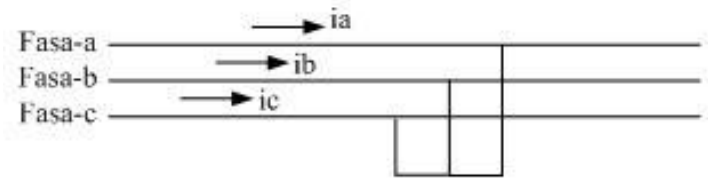

Gambar 2.6. Gangguan hubung singkat tiga fasa

Gangguan hubung singkat tiga fasa termasuk dalam klasifikasi gangguan simetris, dimana arus maupun tegangan setiap fasanya tetap seimbang setelah gangguan terjadi, sehingga pada sistem seperti ini dapat dianalisa hanya dengan menggunakan komponen urutan positif saja, yaitu :

$I_{A}=\frac{V_{f}}{Z_{1}}$

Keterangan :

$V_{f}=$ Tegangan di titik gangguan sesaat sebelum terjadinya gangguan

$\mathrm{Z}_{1}=$ Impedansi urutan positif dilihat dari titik gangguan

$\mathrm{I}_{\mathrm{A}}=$ Arus pada fasa $\mathrm{A}$

\section{METODE PENELITIAN}

Pengambilan data pada penelitian ini dilakukan di PLTU suralaya, yang mana generator diamankan oleh 2 rele differensial. Generator memakai 2 rele differensial adalah untuk berjaga-jaga jika salah satu rele tidak dalam kondisi baik.

\subsection{Data Generator PLTU UP Suralaya Unit 1-4}

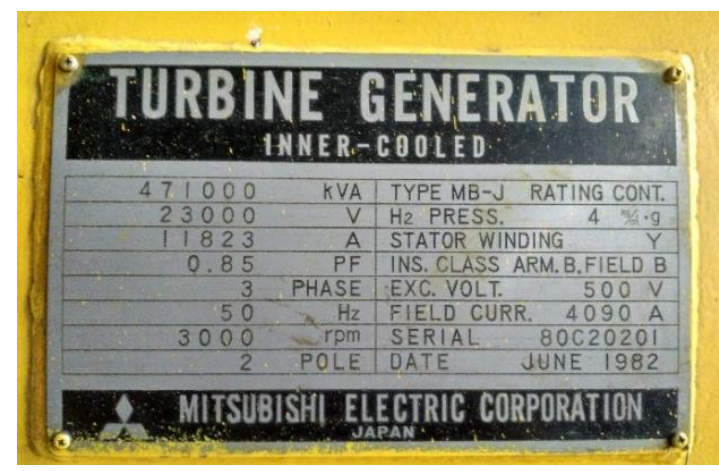

Gambar 3.1. Nameplate Generator 


\subsection{Transformator Utama}

Pabrik pembuat Mitsubishi Electric Corporation, Japan. Tipe Oil Immersed Two Winding Out door. Daya semu 411000/548000/685000 kVA
a. Tegangan primer
: $23 \mathrm{kV}$
b. Arus primer
: $17195 \mathrm{~A}$
c. Tegangan sekunder
: $500 \mathrm{kV}$
d. Arus sekunder
$: 791 \mathrm{~A}$
e. Frekuensi
: $50 \mathrm{~Hz}$
f. Jumlah fasa
$: 3$
g. Uji tegangan tinggi saluran : $1550 \mathrm{kV}$
h. Uji tegangan rendah : $125 \mathrm{kV}$
i. Uji tegangan netral : $125 \mathrm{kV}$
j. Potensi impedansi $\quad: 11,9 \%$ pada 685 MVA

\subsection{Setting Rele Diferensial pada Generator PLTU UP Suralaya Unit 1-4}

Setting of relay $87 \mathrm{G}$

Minimum pickup "Im"

The threshold (Im) is selected taking the $C T$ and relay errors into consideration :

Im $>\lg x$ ct + Iry

$=4.14 \times 0.041+0.10$

$=0.27 \mathrm{~A}$

Setting $=0.40 \mathrm{~A}$

\subsection{Spesifikasi Rele Diferensial pada Generator PLTU UP Suralaya Unit 1-4}

Tabel 3.1. Spesifikasi rele differensial

\begin{tabular}{|c|c|c|c|}
\hline \multirow{2}{*}{\multicolumn{2}{|c|}{$\begin{array}{l}\text { type } \\
\text { Style Number }\end{array}$}} & \multicolumn{2}{|l|}{ TAG-2 } \\
\hline & & PY289 & PY340 \\
\hline \multirow{3}{*}{ CT Circuit } & $\begin{array}{l}\text { Rated } \\
\text { frequency }\end{array}$ & $50 \mathrm{~Hz}$ & $60 \mathrm{~Hz}$ \\
\hline & $\begin{array}{l}\text { Rated } \\
\text { current }\end{array}$ & \multicolumn{2}{|l|}{$5 A A C$} \\
\hline & $\begin{array}{l}\text { Rated } \\
\text { burden }\end{array}$ & \multicolumn{2}{|c|}{ 5VA or less } \\
\hline \multirow{3}{*}{\multicolumn{2}{|c|}{ Operating characteristic }} & \multicolumn{2}{|c|}{$\begin{array}{l}\text { minimum operating } \\
\text { value: } 0,4 \mathrm{~A} \text { fixed }\end{array}$} \\
\hline & & \multicolumn{2}{|c|}{$\begin{array}{l}\text { Operating ratio near } \\
\text { rated value: } 10 \% \\
\text { slope }\end{array}$} \\
\hline & & \multicolumn{2}{|c|}{$\begin{array}{l}\text { Variable ratio: } \\
\text { Above rated value }\end{array}$} \\
\hline \multirow{3}{*}{$\begin{array}{l}\text { Control } \\
\text { circuit }\end{array}$} & Voltage & \multicolumn{2}{|c|}{$\begin{array}{l}\text { 110VDC, allowable } \\
\text { variation range - } \\
20 \% \sim+30 \%\end{array}$} \\
\hline & Burden & \multicolumn{2}{|c|}{$60 \mathrm{~W}$ or less } \\
\hline & $\begin{array}{l}\text { Ext. } \\
\text { resistor }\end{array}$ & \multicolumn{2}{|c|}{$\begin{array}{lr}\text { Paralel } & \text { connection } \\
\text { of three } & 5000 \mathrm{hm} \\
\text { resistors } & (80 \mathrm{~W} \\
\text { rating) } & \end{array}$} \\
\hline
\end{tabular}

\begin{tabular}{|c|c|c|}
\hline \multirow{4}{*}{$\begin{array}{l}\text { Contact } \\
\text { capacity }\end{array}$} & \multirow{2}{*}{ Trip circuit } & $\begin{array}{l}\text { Opening: } 110 \mathrm{VDC} \\
0.3 \mathrm{~A} \text { (less than L/R } \\
40 \mathrm{~ms} \text { ) }\end{array}$ \\
\hline & & $\begin{array}{l}\text { Closing: 110VDC } \\
\text { 15A (resistive load) }\end{array}$ \\
\hline & \multirow{2}{*}{$\begin{array}{l}\text { Alarm } \\
\text { circuit }\end{array}$} & $\begin{array}{l}\text { Opening: } 110 \mathrm{VDC} \\
0.6 \mathrm{~A} \text { (resistive load) }\end{array}$ \\
\hline & & $\begin{array}{l}\text { Closing: 110VDC } \\
\text { 5A (resistive load) }\end{array}$ \\
\hline \multicolumn{2}{|l|}{ Case } & Type D-D5 \\
\hline \multirow{2}{*}{ Weight } & $\begin{array}{l}\text { Relay unit } \\
\text { only }\end{array}$ & $10.0 \mathrm{Kg}$ \\
\hline & with case & $14.5 \mathrm{Kg}$ \\
\hline
\end{tabular}

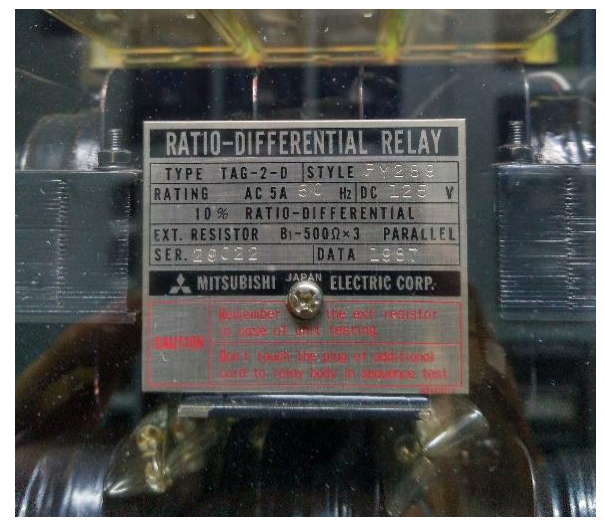

Gambar 3.2. Nameplate rele differensial

\section{HASIL DAN PEMBAHASAN}

4.1. Perhitungan Arus Gangguan

Untuk menghitung arus hubung singkat tiga fasa dan satu fasa ke tanah menggunakan rumus (2.5) dan (2.1) pada bab 2. Data-data yang dibutuhkan untuk menghitung arus hubung singkat sebagai berikut:

Data Generator :

Pabrik pembuat : Mitsubishi Electric Corporation, Japan

Kecepatan putaran

Jumlah fasa

: $3000 \mathrm{rpm}$

Frekuensi

$: 3$

Tegangan

$: 50 \mathrm{~Hz}$

KVA keluaran

$: 23 \mathrm{kV}$

Arus

: 471MVA

Faktor daya

: $11823 \mathrm{~A}$

Rasio hubungan singkat $\quad: 0.5$

Media pendingin

:Gas

Tekanan gas $\mathrm{H}_{2}$

Volume gas

Hidrogen

$: 5 \mathrm{~kg} / \mathrm{cm}^{2}$

$: 125 \mathrm{~m}^{2}$

Tegangan penguat medan $: 500 \mathrm{~V}$

Kumparan

$: \mathrm{Y}$

$\mathrm{X}_{\mathrm{d}}{ }^{\prime}$

$: 0,26 \mathrm{pu}$

$\mathrm{X}_{0}$

$: 0,10 \mathrm{pu}$

Ratio kedua CT 


$\begin{array}{ll}\text { Main transformator } & : 470 \mathrm{MVA} \\ & 500 / 23 \mathrm{KV} \\ \mathrm{X}_{\mathrm{T}} & : 12 \% \\ \mathrm{X}_{0} & : 8 \% \\ \mathrm{X}_{\text {Sistem }} & : \mathrm{j} 0,106 \\ \mathrm{X}_{0 \text { sistem }} & : 0,1 \mathrm{pu}\end{array}$

\subsubsection{Arus Gangguan 3 Fasa}

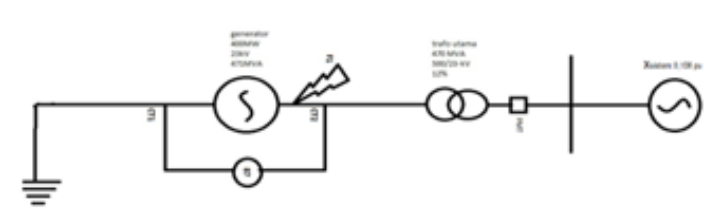

Gambar 4.1 Diagram kelistrikan PLTU Suralaya

Beban maksimum generator $=\frac{471.000}{\sqrt{3} \times 23}=$ 11823 A

Beban arus penuh ini pada sekunder $\mathrm{CT}=$ $11823 \times \frac{5}{15000}=3,941 \mathrm{~A}$

Impedansi berdasarkan basis 100 MVA adalah sebagai berikut:

$\mathrm{X}_{\mathrm{g}}=0,26 \times \frac{100}{471}=j 0,05 \mathrm{pu}$

$\mathrm{X}_{\mathrm{T}}=0,12 \times \frac{100}{470}=j 0,03 p u$

Sistem sumber $=\mathrm{j0}, 106 \mathrm{pu} \quad \mathrm{I}_{\text {basis }}=$ $\frac{100.000}{\sqrt{3} \times 23}=2510,21 \mathrm{~A}$

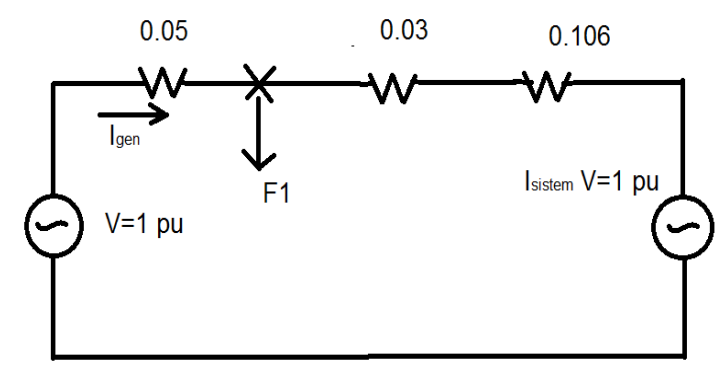

Gambar 4.2 Jala urutan positif

Impedansi pengganti $=\frac{0,05 \times(0,03+0,106)}{0,05+(0,03+0,106}=$ $0,03 p u$

Arus hubung singkat 3 fasa pada titik $\mathrm{F} 1=$ $\frac{V_{f}}{Z_{1}}=\frac{1}{0,03}=33,33 p u$

$=33,33 \times 2510,21=83665,299 \mathrm{~A}$

Arus hubung singkat dari generator $=$

$\frac{0,136}{0,186} \times 83665,299=61174,677 \mathrm{~A}$

Sisi sekunder $\mathrm{CT}=61174,677 \times \frac{5}{15000}=$ 20,391A
Arus hubung singkat dari sistem $=$

$\frac{0,05}{0,186} \times 83665,299=22490,67177 \mathrm{~A}$

Sisi sekunder CT $=22490,67177 \frac{5}{15000}=$ 7,4968 A

Untuk gangguan pada $F 1$, didalam daerah pengamanan rele differensial, dari generator mengalir arus sebesar 20, 391 A melalui CT 1, sedangkan CT 2 mengalir arus sebesar 7,4968 A dari sistem. Arus yang mengalir ke kumparan kerja rele adalah : $\mathrm{I}_{\mathrm{CT} 1}-\mathrm{I}_{\mathrm{CT} 2}=20,391-7,4968=$ 12,8942 A

Arus yang mengalir ke kumparan kerja rele $=12,8942 \mathrm{~A}$

\subsubsection{Arus Gangguan 1 Fasa ke Tanah}

$Z_{1}=Z_{2}=0,03 \mathrm{pu}, \quad R_{n}=0,025 \mathrm{pu}$ Impedansi urutan nol berdasarkan MVA basis:

$\mathrm{Xg}=0,10 \times \frac{100}{471}=0,02 \mathrm{pu}$

$\mathrm{X}_{\mathrm{T}}=0,08 \times \frac{100}{470}=0,01 p u$

$\mathrm{X}_{\text {sistem }}=\mathrm{j} 0,1 \mathrm{pu}$

$I_{\text {basis }}=\frac{100.000}{\sqrt{3} \times 23}=2510,21 \mathrm{~A}$

Impedansi urutan nol pengganti $=$ $\frac{0,02 \times(0,01+0,1)}{0,02+(0,01+0,1)}=0,016 \mathrm{pu}$

Arus hubung singkat 1 fasa ke tanah $=$

$$
\begin{aligned}
\frac{V_{\mathrm{f}}}{Z_{0}+Z_{1}+Z_{2}+3 R n} & =\frac{j \sqrt{3}}{0,016+0,03+0,03+3 \times 0,028} \\
& =10,82531755 \mathrm{pu} \\
& =10,82531755 \times 2510,21 \mathrm{~A} \\
& =27173,82036 \mathrm{~A}
\end{aligned}
$$

Arus hubung singkat dari generator $=$ $\frac{0,11}{0,13} \times 27173,82036=22993,23261 \mathrm{~A}$

Sisi sekunder CT1 $=22993,23261 \times$ $\frac{5}{15000}=7,664410871 \mathrm{~A}$

Arus hubung singkat dari sistem $=$ $\frac{0,02}{0,13} \times 27173,82036=4180,587748 \mathrm{~A}$

Sisi sekunder $\mathrm{CT} 2=$

$4180,587748 \frac{5}{15000}=1,39529249 A$

Untuk gangguan pada $F 1$, didalam daerah pengamanan rele differensial, dari generator mengalir arus sebesar 7,664410871 A melalui CT 1, sedangkan 
CT 2 mengalir arus sebesar 1,39529249A dari sistem sumber. Arus yang mengalir ke kumparan kerja rele adalah perbandingan antara CT 1 dan CT 2 : I IT2 $-\mathrm{I}_{\mathrm{CT} 1}=7,664410871-1,39529249=$ $6,269118381 \mathrm{~A}$

Arus yang mengalir ke kumparan kerja rele $=6,269118381 \mathrm{~A}$

\section{2 . Perhitungan dan Penyetelan Rele Differensial}

Arus Nominal Generator di kedua sisi

CT:

$\mathrm{I}_{1 \& 2}=\frac{M V A}{\sqrt{3} \times K V}=\frac{470.000}{\sqrt{3} \times 23}=11823 \mathrm{~A}$

Perhitungan Missmatch pada Generator

Karena CT pada kedua sisi generator dipasang secara delta maka perhitungan Arus sekunder pada CT kedua sisi generator adalah sebagai berikut:

$$
I_{1 \& 2}=\frac{I_{\text {nominal }}}{\text { ratio } C T}=\frac{11823}{15000 / 5}=3,941 \mathrm{~A}
$$

Selanjutnya menghitung Ratio Trafo Arus Relay yaitu dengan cara :

$$
\begin{aligned}
& I_{F 1 \& 2}=I_{1 \& 2} \times \sqrt{3}=3,941 \times \sqrt{3} \\
& =6,826012233 \mathrm{~A} \\
& S=\frac{I_{F 2}}{I_{F 1}}=\frac{6,826012233}{6,826012233}=1
\end{aligned}
$$

Dari nilai $S=1$ dapat dilihat dari table ratio trafo didapat nilai $\frac{T_{L}}{T_{H}}=\frac{2,9}{2,9}$, maka dari itu bisa dihitung nilai Missmatch:

$$
\begin{aligned}
M=\left(\frac{\frac{I_{L}}{I_{H}}-\frac{T_{L}}{T_{H}}}{\frac{T_{L}}{T_{H}}}\right) \times 100 \% \\
=\left(\frac{\frac{6,826012233}{6,826012233}-\frac{2,9}{2,9}}{\frac{2,9}{2,9}}\right) \\
\times 100 \%=0 \%
\end{aligned}
$$

Karena ratio kedua $\mathrm{CT}$ bagian atas dan bawah generator sama, maka menghasilkan nilai Missmatch sebesar 0\% Arus di Rele Differensial pada saat beban penuh

$$
\begin{aligned}
I_{d}=\left|I_{1}\right|-\left|I_{2}\right| & \\
& =\mid 6,826012233 \\
& -6,826012233 \mid=0 A
\end{aligned}
$$

$$
\begin{aligned}
& I_{r(\text { restrain })}=\frac{I_{1}+I_{2}}{2} \\
& =\frac{6,826012233+6,826012233}{2} \\
& =6,826012233 A
\end{aligned}
$$

Setting Slope

$$
\begin{aligned}
\text { Slope }=\frac{I_{d}}{I_{r}} \times & 100 \% \\
= & \frac{0}{6,826012233} \times 100 \% \\
= & 0 \%
\end{aligned}
$$

Setting Rele Differensial

Minimum Setting $=$ Kesalahan Generator $(\%)+$ Nilai Missmatch (\%) + Error CT (\%) + Toleransi $(\%)+$ Slope (\%)

Minimum Setting $=5 \%+0 \%+5 \%+5 \%+0 \%$ Minimum setting $=15 \%$

Oleh sebab itu dipilih setting $15 \%$ untuk rele differensial

Karena arus hubung singkat terkecil didapat dari arus hubung singkat yaitu sebesar 6,269118381 A maka di ambil $15 \%$ yang didapat dari setting rele.

$6,269118381 \mathrm{~A} \times 15 \%=0,9403677572 \mathrm{~A}$

Dikarenakan setting rele differensial terpasang 0,4 A maka, arus sebesar 0,9403677572 A lebih dari cukup untuk membuat rele differensial bekerja (trip).

\subsection{Analisa Perhitungan}

Gangguan listrik (hubung singkat) yang terjadi di sistem tenaga listrik dapat terjadi antar fasa (3 fasa atau 2 fasa) atau antara fasa dengan tanah, yang disebabkan karena petir, pepohonan, binatang atau tembusnya isolasi pada peralatan di sistem tenaga listrik, seperti generator, trafo, dan lain-lain, untuk mengurangi akibat negatif dari berbagai macam gangguan tersebut maka di perlukan rele pengaman.

Rele pengaman yang dibahas pada skripsi ini adalah penyetingan rele differensial yang terdapat pada generator 400 MW di PLTU Suralaya. Rele ini digunakan sebagai pengaman listrik apabila gangguan hubung singkat terjadi di daerah pengaman rele differensial generator. Cara kerja rele ini membanding arus dari CT1 dan CT2, jika ada perbedaan antara CT1 dan CT2 dan itu 
melewati batas setting rele tersebut maka rele akan bekerja dan memerintahkan perintah putus (tripping) kepada circuit breaker (CB) sehingga peralatan listrik yang terganggu dapat diamankan.

Dalam penyetelan rele differensial di generator PLTU suralaya ini penulis mencari arus hubung singkat terkecil antara arus hubung singkat 3 fasa dan arus hubung singkat 1 fasa ke tanah. Dari perhitungan didapat arus gangguan 3 fasa yang mengalir ke kumparan kerja rele sebesar 12,8942 A dan arus gangguan 1 fasa ke tanah yang mengalir ke kumparan kerja rele adalah 6,269118381 A. Sehingga, nilai arus gangguan yang dipakai untuk perhitungan adalah arus gangguan 1 fasa ke tanah.

Dari perhitungan rele differensial pada generator 400 MW PLTU suralaya diperoleh arus missmatch dan slope $0 \%$. Hal ini disebabkan oleh CT pada kedua sisi generator memiliki ratio yang sama, hal ini dibuat agar rele dapa mendeteksi arus gangguan lebih sensitif. Dari perhitungan menggunakan data-data dari generator 400 MW PLTU suralaya didapat minimum setting $15 \%$.

Karena arus hubung singkat yang terkecil adalah arus hubung singkat 1 fasa ke tanah dan minimum setting yang didapat $15 \%$. Maka, 15\% dari arus hubung singkat 1 fasa ke tanah $(6,269118381 \mathrm{~A})$ diperoleh hasil 0,9403677572 A yang masuk ke kumparan rele differensial. Dikarenakan setting rele differensial terpasang 0,4 A, sehingga arus sebesar 0,9403677572 A sudah cukup untuk membuat rele bekerja dan memberi perintah putus ke pada PMT.

\section{KESIMPULAN}

Simpulan yang didapat dari penelitian ini antara lain sebagai berikut:

1. Arus gangguan 3 fasa yang di dapat dari perhitungan sebesar 12,8942 A

2. Arus gangguan 1 fasa ketanah yang didapat dari perhitungan sebesar $6,269118381 \mathrm{~A}$

3. Setelah rele differensial untuk gangguan dalam generator didapat $15 \%$

4. Arus gangguan terkecil adalah arus gangguan 1 fasa ketanah sehingga menjadi acuan dalam penyettingan rele differensial.

5. Setting rele terpasang pada generator 400 MW PLTU suralaya adalah tepat, yaitu 0,4 A. Karena gangguan terkecil arus yang melalui kumparan rele 0,9403677572 A sudah cukup untuk membuat rele bekerja, yang didapat dari minimum setting (15\%) dari arus gangguan 1 fasa ketanah $(6,269118381 \mathrm{~A})$.

\section{REFERENSI}

1. Djiteng Marsudi Ir, Operasi Sistem Tenaga Listrik (Jakarta : Penerbit Graha IImu, 2006)

2. Sarimun, Wahyudi. (2012). Proteksi Sistem Distribusi Tenaga Listrik. Jakarta: Garamound.

3. Basri, Hasan. (2007). Proteksi Sistem Tenaga Listrik. Jakarta: penerbit ISTN.

4. Narazaki, T. (2008). Study Of Protection Relay Setting. Suralaya: Mitsubishi Electric Corp. Japan. 